\title{
Subcritical water extraction of antioxidants from mountain germander (Teucrium montanum L.)
}

\author{
Nataša Nastića ${ }^{a}$ Jaroslava Švarc-Gajić ${ }^{\mathrm{a}, *}$, Cristina Delerue-Matos ${ }^{\mathrm{b}}$, Simone Morais ${ }^{\mathrm{b}}$, \\ M. Fátima Barroso ${ }^{\mathrm{b}}$, Manuela M. Moreira ${ }^{\mathrm{b}}$

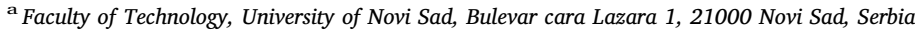 \\ b REQUIMTE/LAQV, Instituto Superior de Engenharia do Instituto Politécnico do Porto, Rua Dr. António Bernardino de Almeida, 431, $4249-015$ Porto, Portugal
}

\begin{abstract}
A B S T R A C T
In the present work, antioxidant compounds from Teucrium montanum were extracted by subcritical water. The influence of extraction temperature and pressure on antioxidant activity of extracts has been investigated in terms of extraction yield (EY), total phenolic content (TPC), and DPPH-radical scavenging activity (DPPH-RSA) and ferric reducing antioxidant power (FRAP). Additionally, the compounds responsible for the antioxidant activity were identified and quantified by high performance liquid chromatography (HPLC). The highest EY (42.63\%), TPC (174.61 $\pm 4.09 \mathrm{mg} \mathrm{GAE} / \mathrm{g} \mathrm{DE})$ and antioxidant activity by DPPH-RSA (176.23 $\pm 8.76 \mathrm{mg}$ TE/g $\mathrm{DE})$ and FRAP (141.71 $\pm 5.21 \mathrm{mg} \mathrm{AAE} / \mathrm{g}$ DE) were seen in extracts obtained at temperature of $160^{\circ} \mathrm{C}$ and pressure of 10 bar. HPLC analysis revealed that naringin and gallic acid were the principle antioxidant compounds in subcritical extracts. According to the results, SWE has a great potential in exploitation of natural sources of bioactive compounds and production of pharmacologically-active fractions.
\end{abstract}

Keywords:

Teucriummontanum

Subcriticalwaterextraction

Antioxidantactivity

Phenoliccompounds

HPLC-PDA

\section{Introduction}

Naturally occurring phenolic compounds have been associated with numerous health-promoting effects such as antioxidant [1], anticarcinogenic [2], antimicrobial [3] and antiviral activity [4]. Other bioactivities which include antimutagenic [5], anti-inflammatory [6] and anti-allergic [7] have been also reported. The antioxidant activity of phenolic compounds is mainly due to their redox properties which allow them to act as reducing agents, hydrogen donors and singlet and triplet oxygen quenchers [8,9]. Phenolic compounds from natural sources are used in food industry for the prevention of lipid peroxidation which is associated with development of off-flavours and other

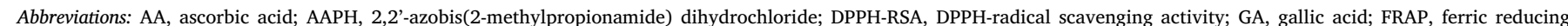

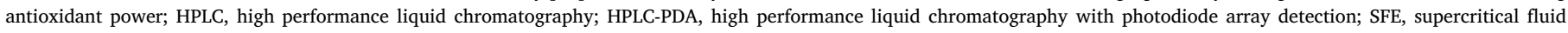
extraction; SWE, subcritical water extraction; TPC, total phenolic content; TPTZ, 2,4,6-tris(2-pyridyl)-s-triazine 
undesirable compounds [10].

Phenolic compounds from plants are isolated by different extraction techniques such as conventional ones, but more recently also by ultrasound extraction [11], microwave-assisted extraction [12] and pressurised liquid extraction [13]. Recently, there has been an increased interest in the use of environmentally clean and safe technologies such as supercritical fluid extraction (SFE) and subcritical water extraction (SWE) [11,14-16]. In addition to the previously mentioned advantages, extracts obtained by SWE usually show higher antioxidant activities in comparison to the ones obtained by conventional solvent $[11,14,16]$ and SFE extraction $[17,18]$.

In the last few decades, SWE has gained much popularity due to the replacement of toxic organic solvents with a safe and low-price solvent. This technique relying on heated and pressurized water improve extraction efficiency, among others, due to lower viscosity of the solvent and consequently better penetration into the pores of solid particles. Subcritical water enhances also mass transfer and desorption kinetics, potentiating the dissociation of the compounds from their complexes with matrix constituents [19]. Recently, a number of papers describing SWE of bioactive compounds from plants have been published $[11,20-22]$.

Chemical profiles of SWE extracts depend on numerous factors such as sample itself, extraction mode and operational parameters. Two major operational parameters governing SWE are temperature and pressure of the extraction. In SWE, temperature has the major influence on the process because slight changes in operational temperature results in water polarity variations. In addition, temperature affects water viscosity and surface tension, as well as the interaction with the matrix [19]. The influence of temperature on bioactivity and composition of subcritical water plant extracts and extraction yields has been studied previously [21,23,24]. Number of scientific evidence evaluated the influence of pressure in SWE, as well $[11,16,25]$. In this work, the influence of both temperature and pressure was investigated and optimised in subcritical water extraction of phenolic compounds from Teucrium montanum.

Many species of Teucrium genus are used in ethnobotany, medicine and pharmacy due to their medicinal properties. T. montanum is used as a diuretic, analgesic and antispasmodic agent, as well as in the treatment of digestive disorders and pulmonary diseases. Some of the bioactive compounds previously identified in $T$. montanum include phenolic acids, mainly gentisic, chlorogenic and siringic, flavonoids, sesquiterpenes, potassium, magnesium and sodium [10,26-28]. According to Vukovic et al. [28], high antimicrobial activity of T. montanum could be associated with sesquiterpenes, such as $\delta$-cadinene and $\alpha$-selinene. Other authors reported that phenolic acids and flavonoids were the principal constituents of T. montanum extracts with antimicrobial and antioxidant activities [29]. Stanković et al. [9] indicated that phenols directly contribute to high antiproliferative and proapoptotic activities of $T$. montanum methanol extracts.

According to available literature, there are no reports on the use of subcritical water for the recovery of bioactive compounds from $T$. montanum. Thus, the aim of this study was to evaluate the efficiency of SWE for obtaining T. montanum extracts with high content of bioactive compounds. The influence of extraction temperature and pressure on antioxidant activity of $T$. montanum extracts has been investigated. Total content of phenolic compounds (TPC) was determined by FolinCiocalteau method. Antioxidant activity of the obtained extracts was essayed by DPPH-radical scavenging activity (DPPH-RSA) and ferric reducing antioxidant power (FRAP). Moreover, the bioactive compounds contributing to the antioxidant activity, namely phenolic compounds, were also identified and quantified by high performance liquid chromatography with photodiode array detection (HPLC-PDA).

\section{Materials and methods}

\subsection{Chemicals and reagents}

Folin Ciocalteau's phenol reagent, sodium carbonate (BioXtra), iron (II) chloride hexahydrate (p.a.), fluorescein sodium salt (for fluorescent tracers), TPTZ (2,4,6-tris(2-pyridyl)-s-triazine; p.a.), Trolox (6-hydroxy2,5,7,8-tetramethylchroman-2-carboxilic acid; purum), gallic acid monohydrate (GA; purum), DPPH and AAPH (2,2'-azobis(2-methylpropionamide) dihydrochloride; granular) were all acquired from SigmaAldrich (Steinheim, Germany). L-(+)-ascorbic acid (AA; p.a.), di-potassium hydrogen phosphate anhydrous (ultrapure) and sodium dihydrogen phosphate monohydrate (p.a.) were from Merck (Darmstadt, Germany). Sodium acetate 3-hydrate (p.a.) was purchased from PanReac AppliChem (Barcelona, Spain). Ethanol absolute anhydrous (p.a.) was acquired from Carlo Erba (Peypin, France). HPLC standards (protocatechuic acid (99.63\%), (+)-catechin ( $\geq 98 \%),(-)$-epicatechin ( $\geq 97 \%)$, vanillic acid ( $\geq 97 \%)$, $\beta$-resorcylic acid ( $\geq 97 \%$ ), chlorogenic acid ( $>95 \%$ ), caffeic acid ( $\geq 98 \%$ ), syringic acid ( $\geq 98 \%$ ), $p$-coumaric acid ( $\geq 98 \%$ ), ferulic acid ( $\geq 99 \%$ ), sinapic acid ( $\geq 99 \%)$, rutin hydrate ( $\geq 94 \%$ ), quercetin (95\%), kaempferol ( $\geq 98 \%$ ), naringin ( $\geq 95 \%$ ), naringenin $(98 \%)$ and cinnamic acid $(\geq 99 \%)$ were purchased from Sigma-Aldrich (Sternheim, Germany) and all solvents employed were HPLC purity grade, filtrated and degassed prior to their use. All aqueous solutions were prepared using ultrapure water $(18.2 \mathrm{M} \Omega \mathrm{cm})$. Nitrogen was of $99.999 \%$ purity (Messer, Germany). All other chemical and reagents were of analytical reagent grade.

\subsection{Plant material}

Commercially available dry T. montanum material was used (Adonis D.O.O., Sokobanja, Serbia). The aerial parts were grounded in a blender, providing an average particle size of $0.34 \mathrm{~mm}$, and stored in dark at ambient temperature.

\subsection{Subcritical water extraction}

SWE was performed in a house-made subcritical water extractor. Extraction procedure and apparatus were described previously [22]. Total capacity of high-pressure stainless-steel vessel was 1.71 . Pressurization of the vessel was performed with nitrogen to prevent possible oxidation. In all experimental runs, sample to distilled water ratio was $1: 10$. Extraction temperature $\left(60-200{ }^{\circ} \mathrm{C}\right)$ and extraction pressure (10-100 bar) were investigated as independent variables, while all other parameters were held constant (agitation rate of $3 \mathrm{~Hz}$ and extraction time of $30 \mathrm{~min}$ ). After extraction, the vessel was cooled and depressurized. Obtained extracts were filtrated and stored in a dark place at $4{ }^{\circ} \mathrm{C}$ until analysis.

\subsection{Determination of extraction yield}

In order to determine extraction yield (EY), certain volume of liquid extracts was evaporated under vacuum at $40^{\circ} \mathrm{C}$. Evaporated extracts were dried at $105^{\circ} \mathrm{C}$ until constant mass. Further calculation of the total extraction yield was done according to the procedure described in pharmacopoeia [30].

\subsection{Determination of total phenolic content}

TPC was determined by a colorimetric assay based on a modified procedure initially described by [31]. The reaction mixture consisted of $25 \mu \mathrm{l}$ of sample or standard solution, $75 \mu \mathrm{l}$ of deionised water and $25 \mu \mathrm{l}$ of Folin-Ciocalteús reagent diluted with water $(1 / 1, v / v)$. After 6 min, $100 \mu \mathrm{l}$ of $\mathrm{Na}_{2} \mathrm{CO}_{3} 7.5 \%(\mathrm{w} / \mathrm{v})$ were added. Absorbance was measured at $765 \mathrm{~nm}$ in a microplate reader (96-well plates, Nunc ${ }^{\mathrm{TM}}$ microwell, Denmark) after $90 \mathrm{~min}$. Calibration curve was defined using GA as a 
standard antioxidant and results were expressed as GA equivalents per $g$ of dry extract (mg GAE/g DE).

\subsection{FRAP assay}

FRAP assay, originally developed by Benzie and Strain [32], was performed with some modifications. Briefly, FRAP reagent $(10 \mathrm{ml}$ of $300 \mathrm{mmol}^{-1}$ acetate buffer ( $\mathrm{pH} 3.6$ ), $1 \mathrm{ml}$ of $10 \mathrm{mmol} \mathrm{TPTZ}$ in $40 \mathrm{mmoll}^{-1} \mathrm{HCl}$, and $1 \mathrm{ml}$ of $20 \mathrm{mmol}^{-1} \mathrm{FeCl}_{3}$ ) was diluted to onethird with acetate buffer. The solution $(180 \mu \mathrm{l})$ was added to each microplate well, along with $20 \mu \mathrm{l}$ of the sample. The control assay was performed using $180 \mu \mathrm{l}$ of FRAP reagent and $20 \mu \mathrm{l}$ of ethanol. Absorbance was measured at $593 \mathrm{~nm}$ at $37^{\circ} \mathrm{C}$. The calibration curve was prepared with ascorbic acid. The results were expressed as AA equivalents per gram of dry extract (mg AAE/g DE).

\subsection{DPPH-RSA assay}

DPPH-RSA of extracts was determined spectrophotometrically at $517 \mathrm{~nm}$, against the stable nitrogen radical DPPH [33]. Briefly, $25 \mu \mathrm{l}$ of the sample was mixed with $200 \mu$ l of ethanolic solution of DPPH $\left(0.04 \mathrm{mg} \mathrm{ml}^{-1}\right)$. The mixture, vigorously shaken, was left to stand for $30 \mathrm{~min}$ in the dark (until stable absorption values). Lower absorbance values of the reactive mixture indicated higher free radical scavenging activity. The calibration curve was prepared with Trolox. Results were expressed as mg of Trolox per gram of dry extract (mg TE/g DE).

\subsection{HPLC-PDA analysis}

HPLC (Shimadzu Corporation, Kyoto, Japan) analysis of phenolic compounds form T. montanum subcritical water extracts was performed on a reverse-phase Phenomenex Gemini-C18 column $(250 \mathrm{~mm} \times 4.6 \mathrm{~mm}, 5 \mu \mathrm{m})$ using the method previously described by Nastić et al. [21]. Samples were eluted using a mobile phase consisting of methanol (solvent A) and water (solvent B) both with $0.1 \%$ formic acid. The composition of the mobile phase varied during the run according to a nonlinear gradient as follows: $85 \% \mathrm{~B}$ in $0 \mathrm{~min}$, from $85 \%$ to $70 \%$ B in $20 \mathrm{~min}$, from $70 \%$ to $55 \%$ B in $20 \mathrm{~min}$, from $55 \%$ to $50 \%$ B in $5 \mathrm{~min}$, from $50 \%$ to $45 \% \mathrm{~B}$ in $5 \mathrm{~min}$, from $45 \%$ to $30 \% \mathrm{~B}$ in $15 \mathrm{~min}$, from $30 \%$ to $0 \% \mathrm{~B}$ in $10 \mathrm{~min}$, followed by $100 \% \mathrm{~A}$ for $5 \mathrm{~min}$ and back to $85 \%$ $B$ in $10 \mathrm{~min}$ and $10 \mathrm{~min}$ of reconditioning before the next injection at a flow rate of $1.0 \mathrm{ml} / \mathrm{min}$. Detection and quantification were performed at 280,320 and $360 \mathrm{~nm}$ according to the phenolic compound maximum wavelength. Identification of compounds in subcritical water extracts was performed by comparing their retention times and UV-vis spectra with those of standard compounds. Peak purity was checked to exclude any contribution from interfering peaks. Individual stock solutions of standard phenolic compounds and their mixtures in methanol-water $(50: 50, \mathrm{v} / \mathrm{v})$ were prepared in methanol $(2000 \mathrm{mg} / \mathrm{L})$ to plot the calibration curves ranging from 1 to $50 \mathrm{mg} / \mathrm{L}$. Quantification of phenolic compounds identified in extracts was performed by interpolating peak areas into corresponding calibration curve. Results were expresses as means (mg/100 g DE) of triplicate injections.

\subsection{Statistical analysis}

All analyses were run in triplicate and the results were expressed as means \pm standard deviation (2SD). Mean values were considered significantly different at $\mathrm{p}<0.05$ confidence level, after the performance of the one-way ANOVA statistical analysis followed by Tuckey test.

\section{Results and discussion}

\subsection{The influence of the extraction pressure}

The aim of the present study was to define optimal conditions for
Table 1

Influence of extraction pressure on EY of T. montanum.

\begin{tabular}{ll}
\hline Pressure (bar) $^{\mathrm{a}}$ & Extraction yield (\%) \\
\hline 10 & 34.58 \\
30 & 37.56 \\
50 & 39.41 \\
80 & 42.12 \\
100 & 40.06 \\
\hline
\end{tabular}

\footnotetext{
a Statistically significant according to one-way analysis of variance (ANOVA). A probability value of $<0.05$ was considered significant.
}

SWE of phenolic compounds from T. montanum. The influence of the extraction pressure on the properties of $T$. montanum subcritical water extracts was observed at five different pressures $(10,30,50,80$ and 100 bar) applying constant extraction temperature $\left(130^{\circ} \mathrm{C}\right)$ and extraction time $(30 \mathrm{~min})$. Table 1 shows extraction yields obtained by SWE at different pressures. The extraction yield was expressed as mass of dry extract ( $\mathrm{g}$ ) per $\mathrm{g}$ of dry plant material, i.e. percentage (\%). Extracts obtained under the pressure of 10 bar demonstrated the lowest EY (34.58\%). Increase in operational pressure from 10 to 80 bar led to increase in EY with the pressure of 80 bar providing the highest EY (42.12\%). According to ANOVA, extraction pressure has shown significant influence on EY at $p<0.05$ confidence level suggesting significant differences between extraction yields obtained at different pressures.

The yield of phenolic compounds recovered for the produced extracts at different pressures was calculated by Folin-Ciocalteu method (Fig. 1). The results presented in Fig. 1 are mean values of three measurements whereas intervals around those values represent 2SD. TPC slightly increased with the increase of pressure from 10 to $80 \mathrm{bar}$, reaching its maximum at 80 bar $(178.63 \pm 17.60 \mathrm{mg} \mathrm{GAE} / \mathrm{g} \mathrm{DE})$. At $100 \mathrm{bar}$, a slight decrease in phenolics yield was observed $(171.09 \pm 14.32 \mathrm{mg} \mathrm{GAE} / \mathrm{g} \mathrm{DE})$. Statistical analysis showed significant difference only between the yields of phenolic compounds obtained at extraction pressures of 10 and $80 \mathrm{bar}(p=0.014)$. In general, results of performed statistical analysis suggested that there were insignificant differences in yields obtained at different pressures, indicating insignificant influence of the extraction pressure. These results were in agreement with the change of water solubility and polarity (dielectric constant) with an increase of pressure. Haar et al. [34] reported that an increase of pressure from 100 to 6000 bar at $25^{\circ} \mathrm{C}$ resulted in a small increase of dielectric constant from 79 to 93 . Higher concentrations of total phenolics were determined in subcritical water extracts of $T$. montanum in comparison to aqueous, methanolic, acetone, ethyl acetate and petroleum ether extracts obtained by conventional solid/liquid extraction [35]. Stanković et al. [35] determined the highest TPC in methanol extract ( $169.06 \mathrm{mg} \mathrm{GAE} / \mathrm{g} \mathrm{DE}$ ), while the lowest content ( $8.33 \mathrm{mg} \mathrm{GAE} / \mathrm{g} \mathrm{DE}$ ) was measured in petroleum ether extract. The authors clearly demonstrated the influence of the solvent on the extraction yield, however other factors such as plant sample itself (variety, geographical region, climate, stress, etc.), mass transfer and extraction technique, should be also taken into consideration.

Antioxidant activity of extracts obtained at different pressures is depicted in Table 2. Similarly as in the case of TPC, extraction pressure did not show marked influence on the antioxidant activities of $T$. montanum extracts. Analysing data from Table 2, increase of pressure from 80 to 100 bar had a negative significant influence on the antioxidant activity $(p<0.05)$. However, performed statistical analysis suggested that there were insignificant differences between activities obtained at other pressures. This fact implies that efficient extraction of phenolic compounds does not require high pressures. The change of the antioxidant activities followed the same trend as in the case of TPC. The highest FRAP activity was determined in the extract obtained at 80 bar $(131.40 \pm 5.83 \mathrm{mg} \mathrm{AAE} / \mathrm{g} \mathrm{DE})$, whereas maximum DPPH-RSA value 


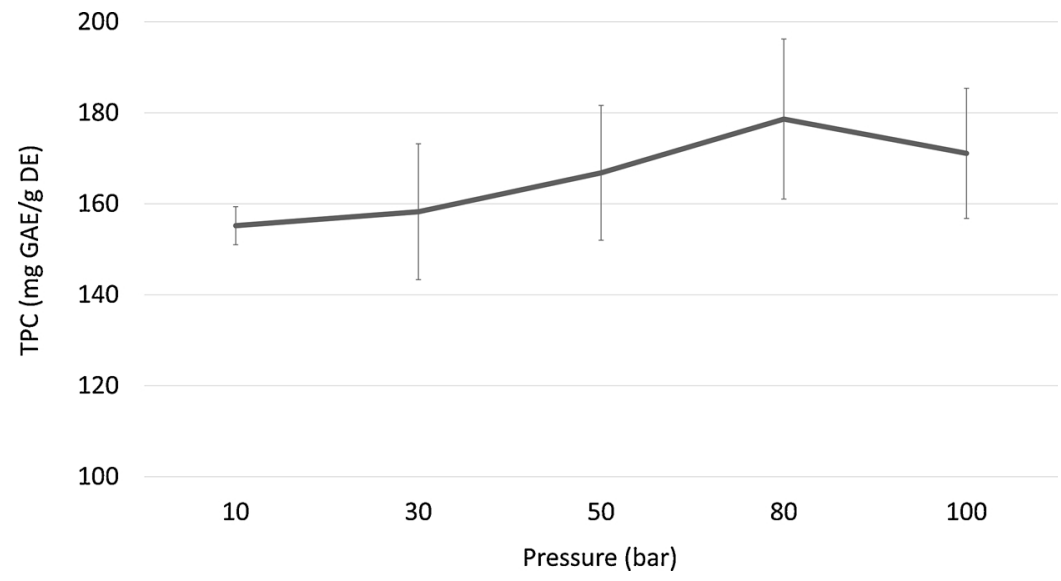

Fig. 1. The influence of the extraction pressure on TPC of T. montanum.

(155.83 $\pm 14.19 \mathrm{mg} \mathrm{TE} / \mathrm{g} \mathrm{DE}$ ) was measured in the extract obtained at 50 bar. The sharp drop in both DPPH-RSA and FRAP activities was observed in extracts obtained at 100 bar. Since the same character of the dependence was seen for TPC, the antioxidant activity of the analysed extracts might have been linked to the phenolic compounds. Other authors that dealt with SWE came to similar conclusions regarding the pressure influence. Investigating the pressure influence on the extraction of phenols from coriander seed, insignificant differences were seen in extracts obtained at pressures from 30 to 90 bar [36]. Aliakbarian et al. [25] also found insignificant effects of the pressure (80-150 bar) on the extraction of phenolic compounds from grape pomace. Cvetanović et al. [37] optimized SWE of chamomile flowers recommending lower pressures for safety reasons and due to insignificant differences in yields of phenolic compounds obtained at 45 and 90 bar.

Since pressure did not significantly affect SWE of phenolic compounds from T. montanum and taking into consideration potential industrial applications, the pressure of 10 bar was chosen as acceptable and was used for further research.

\subsection{The influence of the extraction temperature}

The influence of the extraction temperature on the extraction efficiency was investigated in the range from 60 to $200^{\circ} \mathrm{C}$, applying the adopted extraction pressure ( $10 \mathrm{bar})$. The extraction time ( $30 \mathrm{~min})$ was the same as in the previous experiments. Table 3 shows the dependence of the EY and the temperature, demonstrating that higher extraction yields were reached at higher extraction temperatures. The highest EY (42.63\%) was achieved at $160^{\circ} \mathrm{C}$. Further temperature increase was accompanied with the decrease in the extraction yield. Significantly lower extraction yields (14.44\%) for T. montanum were reported by other authors that applied ultrasound extraction [38]. Results of performed statistical analysis suggested that there were significant differences in yields obtained at different temperature $(p<0.05)$, indicating significant influence of the extraction temperature. Extraction yield was also influenced by the polarity of water (dielectric constant) that affected solubility of the compounds. The dielectric constant of water
Table 3

Influence of extraction temperature on EY of T. montanum.

\begin{tabular}{ll}
\hline Temperature $\left({ }^{\circ} \mathrm{C}\right)^{\mathrm{a}}$ & Extraction yield (\%) \\
\hline 60 & 30.94 \\
100 & 32.66 \\
130 & 34.58 \\
160 & 42.63 \\
200 & 38.23 \\
\hline
\end{tabular}

${ }^{\text {a }}$ Statistically significant according to one-way analysis of variance (ANOVA). A probability value of $<0.05$ was considered significant.

decreases with temperature, increasing the solubility of less polar compounds.

According to ANOVA, extraction temperatures have shown significant influence on TPC at $\quad p<0.05$ confidence level. Performed statistical analysis suggested that there were significant differences between yields of phenolic compounds obtained at different temperatures. With temperature increase from 60 to $160^{\circ} \mathrm{C}$, TPC increased from $143.89 \pm 6.35 \mathrm{mg} \mathrm{GAE} / \mathrm{g} \mathrm{DE}$ to $174.61 \pm 4.09 \mathrm{mg} \mathrm{GAE} / \mathrm{g}$ DE (Fig. 2). Further increase in the extraction temperature to $200{ }^{\circ} \mathrm{C}$ caused a slight decrease in the TPC $(160.60 \pm 4.05 \mathrm{mg} \mathrm{GAE} / \mathrm{g} \mathrm{DE})$. The increase in phenolic content with the temperature could be linked to the decrease in water polarity at higher temperature, and better solubilisation of medium-polarity phenolics. Sumińska et al. [39] examined the effects of temperature on the yield of phenolics from barley straw. The highest TPC was seen when applying extraction temperature of $160^{\circ} \mathrm{C}$. According to Budrat and Shotipruk [40], the most suitable extraction temperature for the recovery of phenolic compounds from bitter melons somewhere between 150 and $200^{\circ} \mathrm{C}$. In the study of Singh and Saladaña [24], TPC increased with temperature up to $180^{\circ} \mathrm{C}$ in SWE of potato peel. Although the same authors concluded that temperatures over $180^{\circ} \mathrm{C}$ lead to pyrolysis, which is associated with the degradation of phenolic compounds.

The antioxidant activities of the subcritical water extracts of $T$. montanum obtained at different temperatures were estimated by DPPH

Table 2

The influence of the extraction pressure on antioxidant activity of T. montanum subcritical water extracts.

\begin{tabular}{|c|c|c|c|c|c|}
\hline \multirow[t]{2}{*}{ Antioxidant activity assay } & \multicolumn{5}{|l|}{ Pressure (bar) ${ }^{b}$} \\
\hline & 10 & 30 & 50 & 80 & 100 \\
\hline DPPH-RSA ${ }^{\mathrm{a}}$ (mg TE/g DE) & $142.43 \pm 4.64$ & $144.59 \pm 11.39$ & $155.83 \pm 14.19$ & $144.29 \pm 14.07$ & $92.83 \pm 4.56$ \\
\hline $\mathrm{FRAP}^{\mathrm{a}}$ (mg AAE/g DE) & $125.27 \pm 10.52$ & $129.69 \pm 4.48$ & $129.86 \pm 6.96$ & $131.40 \pm 5.83$ & $119.96 \pm 1.81$ \\
\hline
\end{tabular}

\footnotetext{
${ }^{\text {a }}$ Mean value $\pm 2 S D$

b Statistically significant according to one-way analysis of variance (ANOVA). A probability value of $<0.05$ was considered significant.
} 


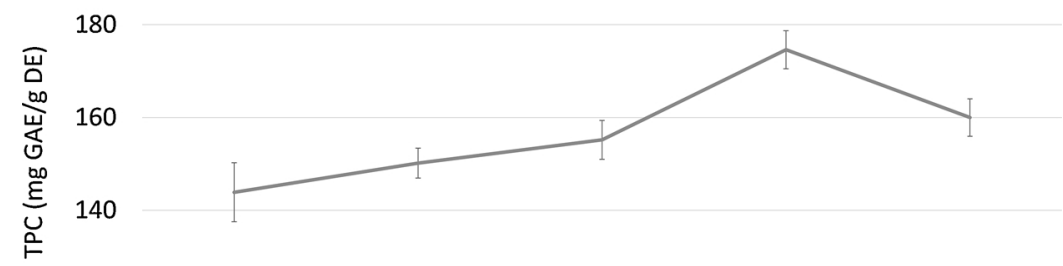

120

100

$\begin{array}{ccccc}60 & 100 & 130 & 160 & 200\end{array}$

Fig. 2. The influence of the extraction temperature on TPC of T. montanum.

a)
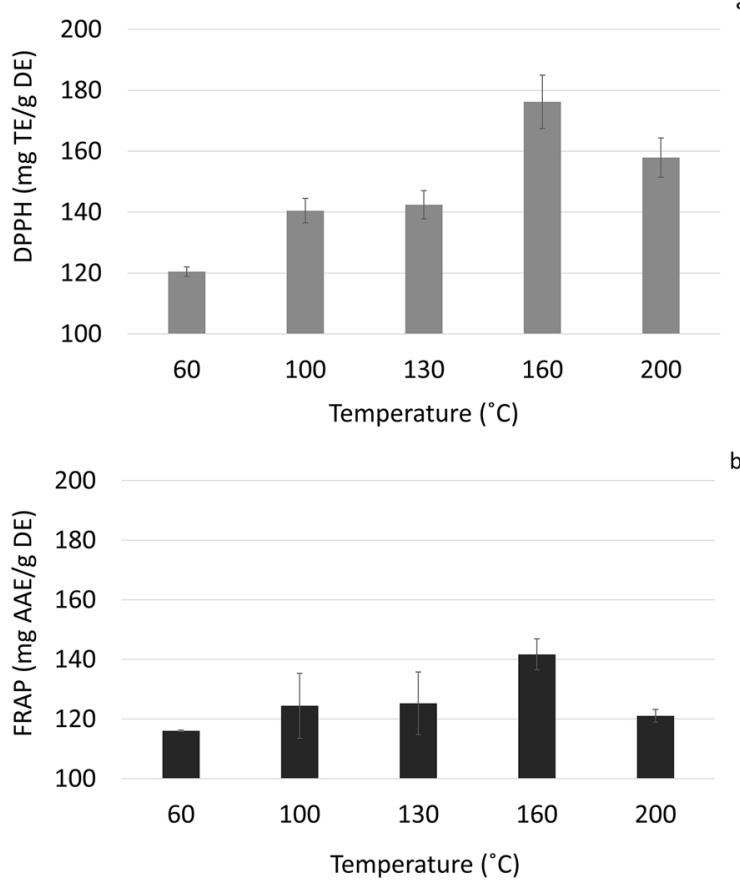

Fig. 3. The influence of the extraction temperature on the antioxidant activity of T. montanum subcritical water extracts: a) DPPH-RSA assay and b) FRAP assay.

and FRAP assays. The results are presented in Fig. 3. Antioxidant activities significantly increased by increasing extraction temperatures from 60 to $160^{\circ} \mathrm{C}$, being in accordance with the TPC. Significant influence of the extraction temperature on antioxidant activity was confirmed by ANOVA statistical analysis $(p<0.01)$. Temperature above $200{ }^{\circ} \mathrm{C}$ caused the decrease in the antioxidant activity probably due to chemical and thermal degradation of the antioxidant compounds from T. montanum. Kumar et al. [20] reported that in SWE of sea buckthorn leaves the temperatures above $150^{\circ} \mathrm{C}$ cause the decrease in antioxidant activity. Similarly, Sharifi et al. [41] reported a decomposition of the heat-sensitive compounds from barberry fruit at temperatures above $157.5^{\circ} \mathrm{C}$ in SWE.

As demonstrated, the extraction of phenolic compounds and the antioxidant activities of SWE extracts of T. montanum depended on the temperature employed. Antioxidant activities significantly increased with the increase in extraction temperature, being in accordance with the content of phenolic compounds. This result suggested that antioxidant activity of $T$. montanum extract may be correlated with the content of phenolic compounds.

\subsection{HPLC-PDA analysis}

The phenolic compounds contributing to the antioxidant activity were identified and quantified by HPLC-PDA analysis (Fig. 4). The extract of T. montanum obtained by subcritical water at temperature of $160{ }^{\circ} \mathrm{C}$, pressure of $10 \mathrm{bar}$, extraction time of $30 \mathrm{~min}$ and agitation rate of $3 \mathrm{~Hz}$ was analysed.

The content of phenolic compounds in the subcritical water extracts was estimated from calibration curves, according to the analytical parameters previously reported by Nastić et al. [21] (Table 4).

According to the results, the main contributor to the phenolic profile and consequently to the antioxidant activity of $T$. montanum extracts is the flavanone naringin which represents $49 \%$ of the total amount of phenolic compounds quantified. Other compounds belonging to the flavonoids were also extracted in high amount, namely two flavan-3ols, (+)-catechin and epicatechin and one flavonol, rutin. Concerning the hydroxybenzoic derivatives, gallic acid was found in high concentration in T. montanum extracts contributing to $17 \%$ of the phenolic composition. On the other hand, vanillic acid $(45.3 \pm 5.1 \mathrm{mg} / 100 \mathrm{~g}$ $\mathrm{DE})$ was recovered in less extent. To the best of our knowledge only few reports were found describing the phenolic composition of this plant $[8,27,38]$. Tumbas et al. [27] investigated the influence of different solvents, namely methanol, petroleum ether, chloroform, ethyl acetate, 1-butanol and water on the TPC as well as the amount of individual phenolic compounds extracted. According to the authors, the 1-butanol extract had the highest TPC $(296 \mathrm{mg} / \mathrm{g})$, while the HPLC analysis revealed that the highest content of phenolic acids $(28.619 \mathrm{mg} / \mathrm{g})$ was found for ethyl acetate extract. Gentisic acid was the most abundant phenolic acid in the ethyl acetate extract $(14.432 \mathrm{mg} / \mathrm{g})$. These authors also quantified other phenolic acids, namely coumaric and syringic acids, which were not detected in the $T$. montanum subcritical water extract. Regarding the chlorogenic, caffeic and vanillic acids, their presence was detected in both studies, but SWE enabled to recover higher amounts of these acids comparing to conventional extraction using water as a solvent, demonstrating the potential of this technique for the recovery of phenolic compounds. In another report [38], the phenolic acid profile of $T$. montanum ethanolic extracts was also investigated, and a similar composition was found. The phenolic composition of diethyl ether extract from T. montanum plant was also analysed by HPLC by Panovska et al. [8]. The authors reported luteolin and diosmetin as the major flavonoids in T. montanum, which were not detected in the T. montanum subcritical water extract produced. These results enable us to conclude that the extraction technique employed for the recovery of phenolic compounds exerts a significant influence. Moreover, they demonstrate the variability for the same plant, but with different geographical origins. 


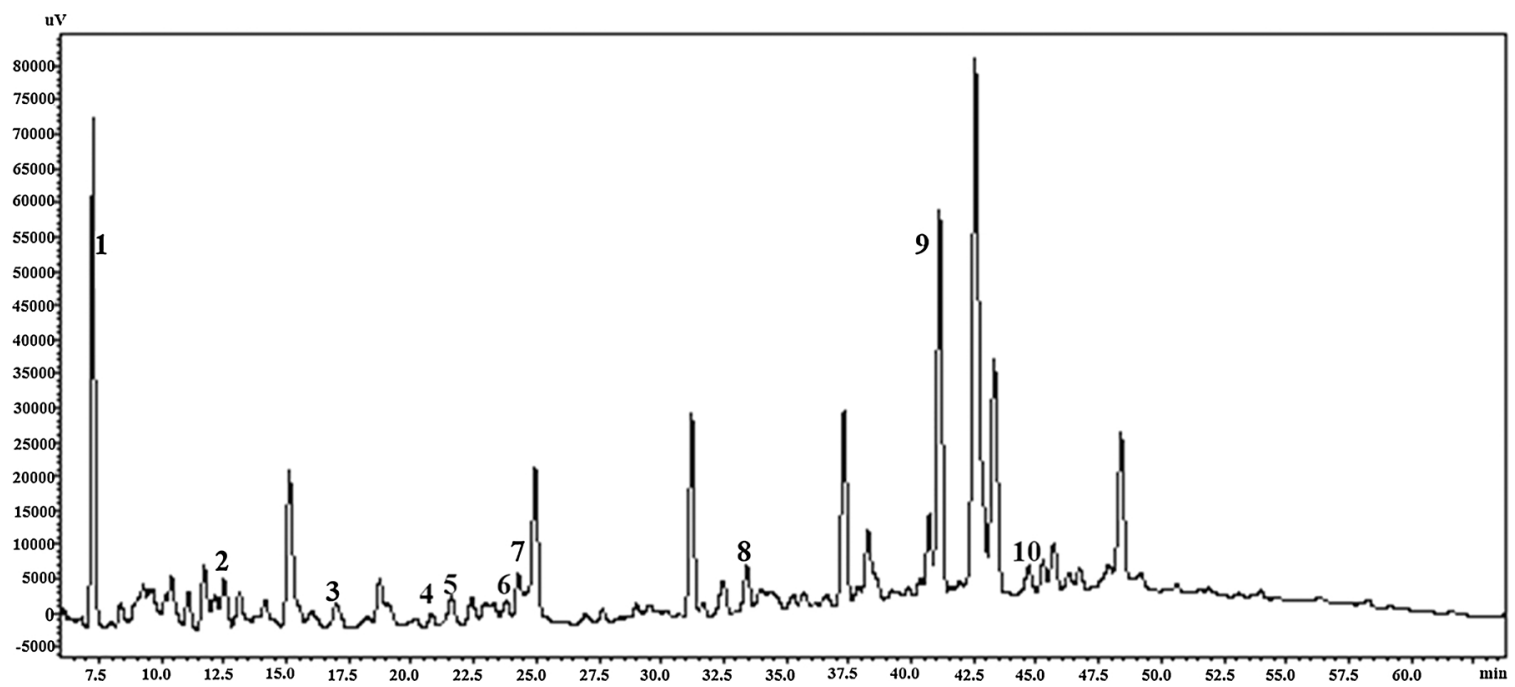

Fig. 4. HPLC chromatogram at $280 \mathrm{~nm}$ for subcritical water extract of T. montanum; gallic acid (1), protocatechuic acid (2), (+)-catechin (3), chlorogenic acid (4), vanillic acid (5), caffeic acid (6), epicatechin (7), ferulic acid (8), naringin (9) and rutin (10).

Table 4

Content of the identified phenolic compounds detected by HPLC-PDA in subcritical water extract of T. montanum; results were expressed as mg/100 g DE.

\begin{tabular}{ll}
\hline Compound & Mean $\pm \mathrm{SD}(\mathrm{mg} / 100 \mathrm{~g}$ dry extract; $\mathrm{n}=3)$ \\
\hline gallic acid & $345 \pm 34$ \\
protocatechuic acid & $117 \pm 12$ \\
(+)-catechin & $115 \pm 12$ \\
chlorogenic acid & $79.9 \pm 8.0$ \\
vanillic acid & $45.3 \pm 5.1$ \\
caffeic acid & $56.0 \pm 6.2$ \\
epicatechin & $120 \pm 12$ \\
ferulic acid & $48.9 \pm 4.9$ \\
naringin & $996 \pm 100$ \\
rutin & $125 \pm 13$ \\
\hline
\end{tabular}

\section{Conclusions}

The results of the present study demonstrate that SWE can be used for the recovery of phenolic compounds from T. montanum aerial parts. Extracts obtained at $160^{\circ} \mathrm{C}$ and 10 bar showed the highest TPC and antioxidant activity. Under optimal extraction conditions, extracts of $T$. montanum yielded EY of $42.63 \%, 174.61 \pm 4.09 \mathrm{mg} \mathrm{GAE} / \mathrm{g}$ DE for TPC and antioxidant activities of $176.23 \pm 8.76 \mathrm{mg} \mathrm{TE} / \mathrm{g}$ DE (DPPH-RSA) and $141.71 \pm 5.21 \mathrm{mg} \mathrm{AAE} / \mathrm{g}$ DE (FRAP). The influence of the extraction pressure on the recovery of phenolic compounds from $T$. montanum was negligible, whereas the temperature influence was statistically significant. Degradation of phenolic compounds from $T$. montanum i.e. the drop in the antioxidant activity, was seen when applying temperatures above $160^{\circ} \mathrm{C}$. Further, HPLC analysis revealed that naringin $(996 \pm 100 \mathrm{mg} / 100 \mathrm{~g} \mathrm{DE})$ and gallic acid $(345 \pm 34 \mathrm{mg}$ / $100 \mathrm{~g}$ DE) were the principal phenolic compounds identified in plant extracts. Based on previous studies on their strong antioxidant activities [21], it can be assumed that those were important contributors to overall antioxidant properties of subcritical water extracts of T. montanum. When compared to extracts obtained by other extraction techniques, subcritical water extracts indicated similar or better recovery of phenolic compounds, not exclusively being related to the extraction technique, but depending also on the sample itself. According to the results, SWE has a great potential in exploitation of natural sources of bioactive compounds and application in food and pharmaceutical industries.

\section{Acknowledgements}

The project 6818 - Transnational Cooperation, Agreement between Portugal (FCT) and Serbia (MSTD) is acknowledged. This work was also funded by project TR 31014 financially supported by the Serbian Ministry of Education, Science and Technological Development. Authors are also grateful for financial support from project NORTE-010145-FEDER-000011-311 Qualidade e Segurança Alimentar-uma abordagem (nano) tecnológica. The financial support from FCT/MEC through national funds and co-financed by FEDER, under the Partnership Agreement PT2020 through the project UID/QUI/50006/ 2013-POCI/01/0145/FEDER/007265, is also acknowledged. M.F. Barroso (SFRH/BPD/78845/2011) and Manuela M. Moreira (SFRH/ BPD/97049/2013) are grateful to Fundação para a Ciência e Tecnologia for their postdoctoral fellowships.

\section{References}

[1] N. Balasundram, K. Sundram, S. Samman, Phenolic compounds in plants and agriindustrial by-products: antioxidant activity, occurrence, and potential uses, Food Chem. 99 (2006) 191-203.

[2] J. Dai, R.J. Mumper, Plant phenolics: extraction, analysis and their antioxidant and anticancer properties, Molecules 15 (2010) 7313-7352.

[3] J.P. Rauha, S. Remes, M. Heinonen, A. Hopia, M. Kähkönen, T. Kujala, K. Pihlaja, P. Vuorela, Antimicrobial effects of Finnish plant extracts containing flavonoids and other phenolic compounds, Int. J. Food Microbiol. 56 (2000) 3-12.

[4] Q.F. Hu, B. Zhou, J.M. Huang, X.M. Gao, L.D. Shu, G.Y. Yang, C.T. Che, Antiviral phenolic compounds from Arundina gramnifolia, J. Nat. Prod. 76 (2013) 292-296.

[5] A. Cardador-Martinez, E. Castano-Tostado, G. Loarca-Pina, Antimutagenic activity of natural phenolic compounds present in the common bean (Phaseolus vulgaris) against aflatoxin B 1, Food Addit. Contam. 19 (2002) 62-69.

[6] L. Zhang, A.S. Ravipati, S.R. Koyyalamudi, S.C. Jeong, N. Reddy, P.T. Smith, J. Bartlett, K. Shanmugam, G. Münch, M.J. Wu, Antioxidant and anti-inflammatory activities of selected medicinal plants containing phenolic and flavonoid compounds, J. Agric. Food Chem. 59 (2011) 12361-12367.

[7] K.C.P. Medeiros, C.A.V. Figueiredo, T.B. Figueredo, K.R.L. Freire, F.A.R. Santos, N.M. Alcântara-Neves, T.M.S. Silva, M.R. Piuvezam, Anti-allergic effect of bee pollen phenolic extract and myricetin in ovalbumin-sensitized mice, J. Ethnopharmacol. 119 (2008) 41-46.

[8] T.K. Panovska, S. Kulenova, M. Stefova, In vitro antioxidant activity of some Teucrium species (Lamiaceae), Acta Pharm. 55 (2005) 207-214.

[9] M.S. Stanković, M.G. Ćurčić, J.B. Žižić, M.D. Topuzović, S.R. Solujić, S.D. Marković, Teucrium plant species as natural sources of novel anticancer compounds: antiproliferative, proapoptotic and antioxidant properties, Int. J. Mol. Sci. 12 (2011) 4190-4205.

[10] J.M. Čanadanović-Brunet, S.M. Djilas, G.S. Ćetković, V.T. Tumbas, A.I. Mandić, V.M. Čanadanović, Antioxidant activities of different Teucrium montanum L. extracts, Int. J. Food Sci. Technol. 41 (2006) 667-673.

[11] A. Cvetanović, J. Švarc-Gajić, P. Mašković, S. Savić, L. Nikolić, Antioxidant and biological activity of chamomile extracts obtained by different techniques: perspective of using superheated water for isolation of biologically active compounds, 
Ind. Crops Prod. 65 (2015) 582-591.

[12] J. Švarc-Gajić, Z. Stojanović, A.S. Carretero, D.A. Román, I. Borrás, I. Vasiljević Development of a microwave-assisted extraction for the analysis of phenolic compounds from Rosmarinus officinalis, J. Food Eng. 119 (2013) 525-532.

[13] M. Ciulu, R. Quirantes-Piné, N. Spano, G. Sanna, I. Borrás-Linares, A. SeguraCarretero, Evaluation of new extraction approaches to obtain phenolic compoundrich extracts from Stevia rebaudiana Bertoni leaves, Ind. Crops Prod. 108 (2017) 106-112.

[14] P. Mašković, V. Veličković, M. Mitić, S. Đurović, Z. Zeković, M. Radojković, A. Cvetanović, J. Švarc-Gajić, J. Vujić, Summer savory extracts prepared by novel extraction methods resulted in enhanced biological activity, Ind. Crops Prod. 109 (2017) 875-881.

[15] V. Veličković, S. Đurović, M. Radojković, A. Cvetanović, J. Švarc-Gajić, J. Vujić, A. Trifunović, P.Z. Mašković, Application of conventional and non-conventional extraction approaches for extraction of Erica carnea L.: chemical profile and biological activity of obtained extracts, J. Supercrit. Fluids 128 (2017) 331-337.

[16] Z. Zeković, A. Cvetanović, J. Švarc-Gajić, S. Gorjanović, D. Sužnjević, P. Mašković, S. Savić, M. Radojković, S. Đurović, Chemical and biological screening of stinging nettle leaves extracts obtained by modern extraction techniques, Ind. Crops Prod. 108 (2017) 423-430.

[17] M.T. Fernández-Ponce, L. Casas, C. Mantell, M. Rodríguez, E.M. de la Ossa, Extraction of antioxidant compounds from different varieties of Mangifera indica leaves using green technologies, J. Supercrit. Fluids 72 (2012) 168-175.

[18] I. Rodríguez-Meizoso, F.R. Marin, M. Herrero, F.J. Señorans, G. Reglero, A. Cifuentes, E. Ibáñez, Subcritical water extraction of nutraceuticals with antioxidant activity from oregano. Chemical and functional characterization, J. Pharm. Biomed. Anal. 41 (2006) 1560-1565.

[19] J. Švarc-Gajić, Sampling and Sample Preparation in Analytical Chemistry, Nova Science Publishers, New York, 2012.

[20] M.Y. Kumar, R. Dutta, D. Prasad, K. Misra, Subcritical water extraction of antioxidant compounds from Seabuckthorn (Hippophae rhamnoides) leaves for the comparative evaluation of antioxidant activity, Food Chem. 127 (2011) 1309-1316.

[21] N. Nastić, J. Švarc-Gajić, C. Delerue-Matos, M.F. Barroso, C. Soares, M.M. Moreira S. Morais, P. Mašković, V. Gaurina-Srček, I. Slivac, K. Radošević, M. Radojković, Subcritical water extraction as an environmentally-friendly technique to recover bioactive compounds from traditional Serbian medicinal plants, Ind. Crops Prod. 111 (2018) 579-589.

[22] J. Švarc-Gajić, A. Cvetanovi ć, A. Segura-Carretero, I.B. Linares, P. Mašković, Characterisation of ginger extracts obtained by subcritical water, J. Supercrit. Fluids 123 (2017) 92-100.

[23] T. Anekpankul, M. Goto, M. Sasaki, P. Pavasant, A. Shotipruk, Extraction of anticancer damnacanthal from roots of Morinda citrifolia by subcritical water, Sep. Purif. Technol. 55 (2007) 343-349.

[24] P.P. Singh, M.D. Saldaña, Subcritical water extraction of phenolic compounds from potato peel, Food Res. Int. 44 (2011) 2452-2458.

[25] B. Aliakbarian, A. Fathi, P. Perego, F. Dehghani, Extraction of antioxidants from winery wastes using subcritical water, J. Supercrit. Fluids 65 (2012) 18-24.

[26] I.J. Cindrić, M. Zeiner, E. Glamuzina, G. Stingeder, Elemental characterisation of the medical herbs Salvia officinalis L. and Teucrium montanum L. grown in Croatia, Microchem. J. 107 (2013) 185-189.

[27] V.T. Tumbas, A.I. Mandić, G.S. Ćetković, S.M. Đilas, J.M. Čanadanović-Brunet, HPLC analysis of phenolic acids in mountain germander (Teucrium montanum L.) extracts, Acta Period. Technol. (2004) 265-273.

[28] N. Vukovic, T. Milosevic, S. Sukdolak, S. Solujic, Antimicrobial activities of essential oil and methanol extract of Teucrium montanum, Evid. Based Complement. Altern. Med. 4 (2007) 17-20.

[29] S.M. Đilas, S.L. Markov, D.D. Cvetković, J.M. Čanadanović-Brunet, G.S. Ćetković, V.T. Tumbas, Antimicrobial and free radical scavenging activities of Teucrium montanum, Fitoterapia 77 (2006) 401-403.

[30] Pharmacopoea Jugoslavica edito qarta (Ph. Jug. IV), Federal Office of Public Health, Beograd, 1984.

[31] V.L. Singleton, J.A. Rossi, Colorimetry of total phenolics with phosphomolybdicphosphotungstic acid reagents, Am. J. Enol. Vitic. 16 (1965) 144-158.

[32] I.F. Benzie, J.J. Strain, The ferric reducing ability of plasma (FRAP) as a measure of "antioxidant power": the FRAP assay, Anal. Biochem. 239 (1996) 70-76.

[33] R.L. Prior, X. Wu, K. Schaich, Standardized methods for the determination of antioxidant capacity and phenolics in foods and dietary supplements, J. Agric. Food Chem. 53 (2005) 4290-4302.

[34] L. Haar, J.S. Gallagher, G.S. Kell, NBS/NRC Steam Tables: Thermodynamic and Transport Properties and Computer Programs for Vapor and Liquid States of Water in SI Units, Hemisphere, Washington DC, 1984.

[35] M.S. Stanković, N. Niciforović, M. Topuzović, S. Solujić, Total phenolic content flavonoid concentrations and antioxidant activity of the whole plant and plant parts extracts from Teucrium montanum L. var. montanum, f. supinum (L.) Reichenb, Biotechnol. Biotechnol. Equip. 25 (2011) 2222-2227.

[36] Z. Zeković, S. Vidović, J. Vladić, R. Radosavljević, A. Cvejin, M.A. Elgndi, B. Pavlić, Optimization of subcritical water extraction of antioxidants from Coriandrum sativum seeds by response surface methodology, J. Supercrit. Fluids 95 (2014) 560-566.

[37] A. Cvetanović, J. Švarc-Gajić, U. Gašić, Ž. Tešić, G. Zengin, Z. Zeković, S. Đurović, Isolation of apigenin from subcritical water extracts: optimization of the process, $\mathrm{J}$. Supercrit. Fluids 120 (2017) 32-42.

[38] S. Vladimir-Knežević, B. Blažeković, M. Kindl, J. Vladić, A.D. Lower-Nedza, A.H. Brantner, Acetylcholinesterase inhibitory, antioxidant and phytochemical properties of selected medicinal plants of the Lamiaceae family, Molecules 19 (2014) 767-782.

[39] P. Sumińska, A. Berton, W. Dietz, Subcritical water extraction (SWE) of barley (Hordeum vulgare) straw as method of antimicrobial and antioxidant additives production, World Sci. News 81 (2017) 169-183.

[40] P. Budrat, A. Shotipruk, Enhanced recovery of phenolic compounds from bitter melon (Momordica charantia) by subcritical water extraction, Sep. Purif. Technol. 66 (2009) 125-129.

[41] A. Sharifi, S.A. Mortazavi, A. Maskooki, M. Niakousari, A.H. Elhamirad, Optimization of subcritical water extraction of bioactive compounds from barberry fruit (Berberis vulgaris) by using response surface methodology, Int. J. Agric. Crop Sci. 6 (2013) 89 . 